\title{
Analisis Kelengkapan Rekam Medis Rawat Inap Rumah Sakit Ganesha Di Kota Gianyar tahun 2019
}

\section{Completeness Analysis of Inpatien Ganesha Hospital Medical Records in Gianyar City in 2019}

\author{
Ni Luh Putu Devhy') \\ Anak Agung Gede Oka Widana2) \\ 1,2)Jurusan Rekam Medis dan Informasi Kesehatan STIKes Wira Medika Bali \\ Dengan alamat Jl. Kecak No. 9A, Gatot Subroto Timur \\ E-mail : deevhy@gmail.com
}

\begin{abstract}
Abstrack
Hospital is an organization engaged in services, therefore it is obliged to hold a medical record for the achievement of good administration. Registration, data filling, processing and analysis as well as documentation, this is the process of organizing medical records. Filling in the medical record is said to be good if each item on the medical record sheet is filled with complete data. A complete medical record is a quality image of a hospital. Based on the above background, the researcher wants to find out the percentage of completeness of medical record filling in the inpatients of Ganesa hospital in the city of Gianyar. This type of research is a descriptive study with a cross-sectional design. The sample in this study was 95 inpatient medical record files. Percentage of completeness for RM Patient identity is $100 \%$, doctor's identity is $96.8 \%$, nurse's identity is $85.3 \%$, informed consent is $95.8 \%$, anesthesia is $43.2 \%$, resume is $100 \%$, diagnosis is $100 \%$, abbreviations of $66.3 \%$, readability of $76.8 \%$, rectification of $23.2 \%$ and structuring of $100 \%$. The incompleteness in filling the inpatient medical record at the Ganesha Gianyar Hospital was highest in the correction item.
\end{abstract}

Keywords: Inpatient Medical Record; Completeness; Hospital

\begin{abstract}
Abstrak
Rumah Sakit merupakan suatu organisasi yang bergerak dibidang pelayanan, oleh karena itu wajib menyelenggarakan rekam medis demi tercapainya administrasi yang baik. Pendaftaran, pengisian data, pengolahan dan analisis serta pendokumentasian, hal tersebut merupakan proses dari penyelenggaraan rekam medis. Pengisian rekam medis dikatakan baik jika setiap item-item pada lembar rekam medis diisi dengan data yang lengkap. Rekam medis yang lengkap merupakan citra mutu dari sebuah rumah sakit tersebut.

Berdasarkan latar belakang diatas peneliti ingin mengetahui persentase angka kelengkapan pengisian rekam medis pada pasien rawat inap rumah sakit Ganesa di kota Gianyar. Jenis penelitian yang digunakan adalah penelitian deskriptif dengan rancangan cross-sectional. Sampel pada penelitian ini adalah berkas rekam medis rawat inap sebanyak 95 rekam medis. Persentase kelengkapan untuk RM Identitas pasien sebesar 100\%, identitas dokter sebesar $96,8 \%$, identitas perawat sebesar $85,3 \%$, informed consent sebesar $95,8 \%$, anestesi sebesar $43,2 \%$, resume $100 \%$, diagnosa sebesar $100 \%$, singkatan sebesar $66,3 \%$, keterbacaan sebesar $76,8 \%$, pembetulan sebesar $23,2 \%$ dan penataan sebesar $100 \%$. Ketidakengkapan pada pengisian rekam medis rawat inap di Rumah Sakit Ganesa Gianyar yang paling tinggi pada item pembetulan.
\end{abstract}

Kata kunci: Rekam Medis Rawat Inap; Kelengkapan; Rumah Sakit 


\section{Pendahuluan}

Rumah sakit merupakan suatu organisasi yang bergerak di bidang pelayanan kesehatan yang setiap hari berhubungan dengan pasien. Rumah sakit sebagai salah satu sub sistem pelayanan kesehatan yang memberikan pelayanan kesehatan mencakup pelayanan medik, rehabilitasi medik dan pelayanan perawatan. Pelayanan tersebut dilaksanakan melalui unit gawat darurat, unit rawat jalan dan unit rawat inap (Muninjaya, 2012). Pada era globalisasi ini rumah sakit harus mempersiapkan diri, agar siap bersaing dengan yang lain. Perkembangan teknologi menyebabkan permintaan dan tuntutan terhadap rumah sakit untuk menyediakan pelayanan kesehatan yang cepat dan profesional terhadap kebutuhan informasi medis. Melayani pasien adalah salah satu bentuk pelayanan rumah sakit, maka dari itu rumah sakit memiliki kewajiban untuk menjalankan rekam medis dengan baik.

Rekam medis merupakan catatan atau informasi baik secara tertulis maupun terekam mengenai siapa, apa, mengapa, bagaimana pelayanan yang diberikan pada pasien tersebut. Rekam medis yang lengkap dan benar dapat digunakan untuk berbgai keperluan. Keperluan tersebut antara lain sebagai bahan bukti untuk dipengadilan, Pendidikan dan pelatihan, serta dapat digunakan untuk bahan evaluasi mutu pelayanan rumah sakit (Winarti \& Supriyanto, 2013).

Ketidaklengkapan informasi dalam pengisian rekam medis dapat menjadi masalah, karena rekam medis dapat memberikan informasi terinci tentang apa yang sudah terjadi kepada pasien selama berada di rumah sakit, hal ini pun berdampak pada mutu rekam medis serta terhadap pelayanan yang diberikan terhadap rumah sakit.

Menurut Peraturan Menteri Kesehatan Nomor 269/MENKES/PER/III/2008, syarat rekam medis yang bermutu adalah: terkait kelengkapan isian rekam medis; keakuratan; ketepatan catatan rekam medis; ketepatan waktu; dan pemenuhan persyaratan aspek hukum. Sedangkan jika mengacu pada pedoman standar pelayanan minimal (SPM) rumah sakit, terdapat empat indikator sasaran mutu yang salah satunya ketepatan waktu penyediaan dokumen rekam medis (Departemen Kesehatan Republik Indonesia, 2008).

Dari hasil penelitian yang berjudul Analisis Kelengkapan Pengisian Resume Medis Pasien Hyperplasia Of Prostate Pada Dokumen Rekam Medis Rawat Inap Di Rumah Sakit Mulia Hati Wonogiri Tahun 2013 menyebutkan bahwa kelengkapan review identifikasi dokumen rekam medis yang diisi pada item nama sebesar 34 DRM (41\%), item jenis kelamin sebesar 35 DRM (42\%), item nomor rekam medis sebesar 35 DRM (42\%). Berdasarkan standar pelayanan minimal menurut Depkes RI tahun 2006 dikatakan lengkap itu mencapai $100 \%$, sehingga kelengkapan DRM di Rumah Sakit Mulia Hati Wonogiri belum lengkap (Meigian, 2014)

Berbagai usaha telah dilakukan oleh rumah sakit untuk pemenuhan pengisian rekam medis misalnya seperti membuat SOP tentang review pendokumentasian yang benar agar seluruh petugas rekam medis terkait dapat bekerja menurut kebijakan yang ditetapkan di rumah sakit, kemudian rumah sakit juga sudah melakukan sosialisai keseluruh petugas rekam medis tentang keharusan pengisian rekam medis. Berdasarkan uraian diatas, peneliti tertarik untuk melakukan penelitian tentang "Analisis Kelengkapan Pengisian Rekam Medis Rawat Inap Rumah Sakit Ganesha Di Kota Gianyar Tahun 2019".

\section{Metode}

Jenis penelitian ini adalah metode penelitian deskriptif, yaitu penelitian yang 
bertujuan untuk melihat gambaran atau fenomena yang terjadi didalam populasi tertentu, dengan rancangan cross -sectional. Penelitian ini dilakansanakan pada bulan Agustus 2019. Sampel dalam penelitian ini adalah rekam medis rawat inap Rumah Sakit Ganesa di Kota Gianyar Tahun 2019 sebanyak 95 rekam medis.

Instrumen penelitian ini berupa cheeklist observasi digunakan untuk mengetahui kelengkapan isi rekam medis.

Tabel 1. Definisi Operasional

\begin{tabular}{lllll}
\hline Variabel & $\begin{array}{c}\text { Definisi } \\
\text { Operasio } \\
\text { nal }\end{array}$ & $\begin{array}{c}\text { Alat } \\
\text { Ukur }\end{array}$ & $\begin{array}{l}\text { Hasil } \\
\text { Ukur }\end{array}$ & $\begin{array}{l}\text { Skala } \\
\text { Ukur }\end{array}$ \\
\hline Keleng & $\begin{array}{l}\text { Pengisian } \\
\text { kapan } \\
\text { dokumen }\end{array}$ & $\begin{array}{l}\text { Daf } \\
\text { tar }\end{array}$ & $\begin{array}{l}\text { Leng } \\
\text { kap, }\end{array}$ & Nom \\
inal \\
Mekam & rekam & cheek & tidak & \\
untuk & medis & list & leng & \\
pasien & & & kap & \\
rawat & & & & \\
inap & & & & \\
& & & &
\end{tabular}

\section{Hasil dan Pembahasan}

\section{Hasil}

Penlitian ini dilaksanakan di Rumah Sakit Ganesha Di Kota Gianyar pada bulan Agustus 2019. Jumlah sampel yang digunakan yaitu rekam medis rawat inap sebanyak 95 rekam medis.

Tabel 2. Persentase Kelengkapan Rekam Medis Rawat Inap Rumah Sakit Gianyar di Kota Gianyar Tahun 2019

\begin{tabular}{lr}
\hline Variabel & $\mathbf{n = 9 5}$ \\
\hline Identitas Pasien & \\
Lengkap & $95(100)$ \\
$\quad$ Tidak lengkap & \\
Identitas dokter & \\
$\quad$ Lengkap & $92(96,8)$ \\
Tidak lengkap & $3(3,2)$ \\
Identitas perawat & \\
Lengkap & $81(85,3)$ \\
Tidak lengkap & $44(14,7)$ \\
Informed consent & \\
Lengkap & $91(95,8)$ \\
Tidak lengkap & $4(4,2)$
\end{tabular}

\begin{tabular}{ll}
$\begin{array}{l}\text { Anastesi } \\
\text { Lengkap }\end{array}$ & $41(43,2)$ \\
Tidak lengkap & $54(56,8)$ \\
Resume & \\
$\quad$ Lengkap & $95(100)$ \\
Tidak lengkap & \\
Diagnosa & \\
$\quad$ Lengkap & $95(100)$ \\
Tidak lengkap & \\
Singkatan & \\
Lengkap & $63(66,3)$ \\
Tidak lengkap & $32(33,7)$ \\
Keterbacaan & \\
$\quad$ Lengkap & $73(76,8)$ \\
Tidak lengkap & $22(23,2)$ \\
Pembetulan & \\
Lengkap & $22(23,2)$ \\
Tidak lengkap & $73(76,8)$ \\
Penataan & \\
Lengkap & $95(100)$ \\
Tidak lengkap & \\
\hline Sumber data : pribadi &
\end{tabular}

Berdasarkan Tabel 2 diketahui bahwa persentase kelengkapan identifikasi pasien pada RM rawat inap di rumah sakit Ganesa sebanyak 95\% RM, kelengkapan identitas dokter pada RM rawat inap di rumah sakit ganesa sebanyak 96,8\% RM dan tidak lengkap sebanyak 3,2\% RM sedangkan persentase kelengkpan identitas perawat pada $\mathrm{RM}$ rawat inap di rumah sakit ganesa didapatkan sebanyak 85,3\% RM dan tidak lengkap sebanyak 14,7\% RM. Persentase kelengkapan rekam medis rawat inap di Rumah Sakit Ganesa di Kota Gianyar didapatkan sebesar 95,8\% RM dan tidak lengkap sebesar 4,2\% RM, persentase untuk RM anastesi didapatkan yang lengkap sebesar 43,2\% RM dan tidak lengkap sebesar 56,8\% RM, kelengkapan RM anastesi sebesar 100\% RM.

\section{Pembahasan}

Berdasarkan hasil penelitian tersebut masih ditemukan beberapa item yang tidak lengkap yaitu, identitas dokter, identitas perawat, inform consent, anastesi, singkatan, keterbacaan dan pembetulan.

Seperti kita ketahui bersama salah satu tujuan dari rekam medis adalah aspek administrasi yang artinya suatu 
berkas rekam medis menyangkut tindakan berdsarkan wewenang, tanggung jawab sebagai tenaga medis dan paramedis dalam mencapai tujuan pelayanan (Hatta, 1985)

Ketidaklengkapan pengisian RM rawat inap Rumah Sakit Ganesa di Kota Gianyar ini dapat menghambat petugas RM dalam penginputan, pengolahan data dan pembuatan pelaporan dalam bentuk informasi kegiatan pelayanan kesehatan yang tidak tepat waktu. Diminimalkan dengan mencari solusi dari masalah penyebab ketidaklengkapan pengisisan RM rawat inap. Penelitian ini sejalan dengan penelitian di Rumah Sakit Umum Rizki Amalia yang mengatakan bahwa kelengkapan rekam medis rawat inap belum semua item mencapai $100 \%$. Hal ini terjadi karena sering kali dokter penanggung jawab pasien belum melengkapi formulir rekam medis, sehingga rekam medis yang tidak lengkap dikembalikan ke perawat untuk dilengkapi (Herissa, 2017).

Rekam medis adalah yang berisikan catatan dan dokumen tentang identitas pasien, pemeriksaan, pengobatan, tindakan dan pelayanan lain yang diberikan kepada pasien. Rekam medis harus dibuat secara tertulis, lengkap dan jelas atau secara elektronik. Isi rekam untuk medis pasien rawat inap dan perawatan satu hari sekurang-kurangnya (Permenkes RI No. $269,2008)$.

\section{Simpulan dan Saran}

\section{Simpulan}

Berdasarkan hasil penelitian diatas didapatkan kesimpulan :

Persentase kelengkapan untuk RM Identitas pasien sebesar $100 \%$, identitas dokter sebesar 96,8\%, identitas perawat sebesar 85,3\%, informed consent sebesar $95,8 \%$, anastesi sebesar $43,2 \%$, resume $100 \%$, diagnose sebesar $100 \%$, singkatan sebesar $66,3 \%$, keterbacaan sebesar 76,8\%, pembetulan sebesar $23,2 \%$ dan penataan sebesar $100 \%$.

\section{Saran}

Bagi petugas rekam medis, perlu memiliki kesadaran dan kedisiplinan kepada petugas Asembling dalam melengkapi RM dengan cara sosilisasi kepada perawat, dokter yang bersangkutan.

Bagi dokter dan perawat agar lebih memahami pentingnya kegunaan resume medis diisi lengkap. Maka dari itu diharapkan setiap meja kerja ditempelkan kewajiban untuk mengisi resume rekam medis dengan cara yang sudah ditentukan.

Bagi rumah sakit perlu membuat SOP tentang review pendokumentasian yang benar sehingga petugas kesehatan bekerja sesuai dengan aturan yang telah dibuat.

\section{Ucapan Terima Kasih}

Terima kasih disampaikan kepada STIKes Wira Medika Bali yang telah mendanai keberlangsungan penelitian ini. Terimakasih juga disampaikan kepada Rumah Sakit Ganesha yang sudah memberikan kesempatan kepada kami untuk melakukan penelitian. Terima kasih buat enumerator yang sudah membantu berjalannya penelitian ini, serta kepada pihak yang tidak bisa disebutkan satu persatu.

\section{Daftar Pustaka}

Departemen Kesehatan Republik Indonesia. (2008). Standart Pelayanan Minimal Rumah Dirjen Bina Pelayanan Medik. Jakarta.

Hatta, G. (1985). Catatan Medik Dalam Kedudukannya Sebagai Penunjang Sistem Kesehatan Nasional (13th ed.). Jakarta: Bulletin Medical Record.

Herissa, D. C. (2017). Analisis Kelengkapan Rekam MEdis Rawat Inap Di Rumah SAkit Umum Rizki Amalia Kulon Progo Yogyakarta Tahun 2017. Retrieved from http://repository.unjaya.ac.id/2115/ 2/DYAS CANDRA HERISA_1313034_pisah.pdf

Meigian, A. H. (2014). Analisis kelengkapan pengisian resume medis pasien. 
Retrieved from

http:/ / eprints.ums.ac.id/32431/23/0

2. NASKAH PUBLIKASI.pdf

Muninjaya, A. (2012). Manajemen Kesehatan (3rd ed.). Tangerang: EGC.

Permenkes RI No. 269, T. 200. (2008).

Permenkes RI No. 269 Th. 2008.
Menteri Kesehatan, pp. 1-7.

Winarti, \& Supriyanto, S. (2013). Analisis Kelengkapan Pengisian dan Pengembalian Rekam Medis Rawat Inap Rumah Sakit. Administrasi Kesehatan Indonesia, 1(4), 345-351. 